\title{
RESEARCH
}

Open Access

\section{Serum IncRNA-ANRIL and SOX9 expression levels in glioma patients and their relationship with poor prognosis}

\author{
Youlu Sun 1 , Yuesong Jing ${ }^{2}$ and Yuxin Zhang ${ }^{1 *}$
}

\begin{abstract}
Background: IncRNA-CDKN2B antisense RNA 1 (ANRIL) and SRY-box transcription factor 9 (SOX9) has abnormal expression in many tumors including glioma, but the underlying molecular mechanism is unclear. This study set out to investigate the serum InCRNA-ANRIL and SOX9 levels in glioma patients and their effects on prognosis.
\end{abstract}

Methods: We enrolled 142 glioma patients admitted to our hospital from May 2014 to May 2016 into the research group $(R G)$ and 120 healthy subjects receiving concurrent physical examinations into the control group (CG). Fasting peripheral blood (4 mL each) was sampled from subjects from the two groups. Using the quantitative realtime polymerase chain reaction (qRT-PCR), InCRNA-ANRIL and SOX9 were measured to explore their values in the early diagnosis of glioma. Patients from RG were followed up for 3 years to analyze the influence of IncRNA-ANRIL and SOX9 on patient prognosis. We purchased glioma cell lines U251 and U87 and grouped them according to the transfection of different plasmids. We conducted CCK8 assay to test cell proliferation, Transwell assay to test cell invasion, the flow cytometry to test cell apoptosis, and Western Blot assay to measure bcl-2 and bax protein levels.

Results: ANRIL and SOX9 were evidently higher in RG than in CG $(P<0.01)$. The receiver operating characteristic (ROC) curve revealed that the diagnostic sensitivity of ANRIL combined with SOX9 for glioma was $81.62 \%$, and the specificity was $90.83 \%(P<0.01)$. ANRIL and SOX9 were closely related to tumor grade, tumor diameter, distant metastasis, and family history of glioma $(P<0.01)$. In total, 135 patients were successfully followed up (95.07\%). Patients with high levels of ANRIL and SOX9 had a markedly poorer prognosis than those with low levels $(P<0.05)$. ANRIL and SOX9 were markedly higher in glioma cell lines (U251 and U87) than in normal brain cells $(P<0.01)$. The proliferation and invasion of U251 cells were notably reduced after the transfection of ANRIL and SOX9 inhibitory sequences $(P<0.01)$, but the apoptosis was notably increased $(P<0.01)$. Bcl-2 expression was markedly increased in IncRNA-ANRIL-inhibitor and SOX9-inhibitor $(P<0.01)$, while bax expression was markedly reduced in IncRNA-ANRILinhibitor and SOX9-inhibitor $(P<0.01)$.

Conclusion: IncRNA-ANRIL and SOX9 levels were higher in glioma patients than in healthy people. High-IncRNAANRIL and SOX9 levels were strongly associated with unfavorable prognosis of patients. The testing of biological behaviors revealed that IncRNA-ANRIL and SOX9 worked as tumor-promoting genes in glioma.

Keywords: IncRNA-ANRIL, SOX9, Glioma, Prognosis, Proliferation, Invasion

\footnotetext{
* Correspondence: zm2s8p@163.com

'Department of Neurosurgery, Guangrao County People's Hospital, No. 180

Huayuan Road, Dongying, Guangrao County 257300, P.R. China

Full list of author information is available at the end of the article
}

(c) The Author(s). 2021 Open Access This article is licensed under a Creative Commons Attribution 4.0 International License, which permits use, sharing, adaptation, distribution and reproduction in any medium or format, as long as you give appropriate credit to the original author(s) and the source, provide a link to the Creative Commons licence, and indicate if changes were made. The images or other third party material in this article are included in the article's Creative Commons licence, unless indicated otherwise in a credit line to the material. If material is not included in the article's Creative Commons licence and your intended use is not permitted by statutory regulation or exceeds the permitted use, you will need to obtain permission directly from the copyright holder. To view a copy of this licence, visit http://creativecommons.org/licenses/by/4.0/ The Creative Commons Public Domain Dedication waiver (http://creativecommons.org/publicdomain/zero/1.0/) applies to the data made available in this article, unless otherwise stated in a credit line to the data. 


\section{Introduction}

Glioma, mainly arising from neural stem or progenitor cells [1], is the most common malignancy of the central nervous system [2,3] and accounts for about $80 \%$ of intracranial malignancies. It is featured with high morbidity, high recurrence rate, and high mortality, and its relative 5-year survival is as low as 5\%. Glioma mostly attacks adults, especially those aged 30-40 years [4, 5]. Most gliomas are featured with an infiltrative spreading to the surrounding central nervous parenchyma [6]. The World Health Organization (WHO) divides glioma into 4 grades: grades I and II are low-grade gliomas, including astrocytomas and oligodendroglioma, with a long course of disease, and grades III and IV are high-grade gliomas, including anaplastic gliomas and glioblastomas [7]. Untreated gliomas can easily lead to deaths [8]. Existing clinical treatments of gliomas mainly include surgery combined with radiotherapy and chemotherapy $[9,10]$. However, complete removal of glioma through surgery is difficult due to its invasive growth, not alone the high recurrence rate after the surgery $[11,12]$. The exploration of the mechanisms of the proliferation and invasion of glioma cells has been a hot topic recently, aiming to identify genes and molecular mass targets that inhibit glioma tumor growth.

Long non-coding RNA (lncRNA) is involved in regulating various biological processes of the body [13, 14]. The abnormal expression of lncRNAs plays a crucial part in the progression of a variety of cancers including gliomas $[15,16]$. LncRNA-CDKN2B antisense RNA 1 (ANRIL) is located in the inhibitors of cyclin dependent kinase 4. The study by Dong et al. [17] proposed that the antisense lncRNA in lncRNA-ANRIL variants is associated with gliomas. SRY-box transcription factor (SOX) genes, belonging to a family of transcription factors that contain HMG (high-mobility group) domains, have many target molecules and play a role in cell differentiation during embryonic development $[18,19]$. SOX9 has abnormal expression in many tumors including glioma [20], but the underlying molecular mechanism is unclear [21].

In the process of tumor pathogenesis, the multiplication and invasion of tumor cells are crucial, which determines whether the tumor cell cycle can progress smoothly. Here we first tested the expression of IncRNA-ANRIL and SOX9 in normal adults and glioma patients to analyze the effects of the two genes on the prognosis of glioma patients. After transfecting glioma cell lines with ANRIL and SOX9 inhibitory sequences, we measured apoptosis-related proteins (bcl-2 and bax) to observe changes in multiplication, invasion, and apoptosis in glioma cell lines. We aimed to enlighten new ways to regulate glioma cell proliferation and invasion, to explore the possibility of IncRNA-ANRIL and SOX9 to act as new targets for glioma gene therapy, and to provide a reliable reference for future clinical research and diagnosis of gliomas.

\section{Materials and methods \\ Basic information}

We enrolled 142 glioma patients admitted to our hospital from May 2014 to May 2016 into the research group (RG) and 120 healthy subjects receiving concurrent physical examinations into the control group (CG). The average age of all research subjects was (34.58 \pm 5.65$)$ years. This experiment has been approved by the hospital ethics committee, and the signed informed consent was obtained from all subjects or their immediate family members.

\section{Inclusion and exclusion criteria}

Inclusion criteria: All patients were treated in our hospital for the first time and were all in line with the diagnosis of glioma after pathological examination. No benign or malignant tumor disease was found in this group of healthy subjects. Exclusion criteria: (1) Patients with prior treatments such as surgery; (2) patients with comorbid cardiovascular, liver, kidney, and other diseases; (3) patients with incomplete pathological data; (4) patients with other malignancies with brain metastases; (5) patients with systemic infection or nervous system disease; (6) patients with mental disorders who cannot cooperate with treatment; and (7) patients with endstage disease.

\section{Experimental reagents and materials}

Normal human astrocytes (HA) and U251 and U87 of glioma cell lines were provided by BeNa Culture Collection (Beijing, BNCC337972, BNCC100123, BNCC337885). DMEM and PBS were obtained from Gibco (USA, 1142802). Trypsin was from Shanghai Shifeng Biological Technology Co., Ltd. (EB04590). RPMI1640 culture medium, ANNEXIN V-FITC/PI apoptosis detection kit, and BCA protein kit were purchased from Shanghai Jingke Chemical Technology Co., Ltd. (GNM-31800, AD10-2, JK-201a). Trizol kit and reverse-transcription kit were manufactured by Shanghai Kanglang Biotechnology Co., Ltd. (KL058, KL266). LncRNA quantitative real-time polymerase chain reaction (qPCR) kit was from Beijing Bai'ao Laibo Technology Co., Ltd. (WH0125-MXG). Cell counting kit-8 (CKK8) was from Goyoo Bio Co., Ltd. (GY025). ECL Ultra Reagent was manufactured by Shanghai Chuan Qiu Biotechnology Co., Ltd. (HE-60). The HRP-labeled secondary antibody was from Shanghai Yuduo Biotechnology Co., Ltd. (YDJ3235). The microplate reader was from BioTek Instruments, Inc. (USA, PerkinElmer). FC500MCL flow cytometer was from BD (USA, 
FACS Canto II). Design, and synthesis of all primer sequences were undertaken by Sangon Biotech (Shanghai).

\section{Cell culture and transfection Cell culture}

Glioma cells (U251 and U87) were cultivated in DMEM comprising $10 \% \mathrm{PBS}$ in an incubator at $37^{\circ} \mathrm{C}$ with $5 \%$ $\mathrm{CO}_{2}$.

\section{Cell transfection}

The day before transfection, glioma cells were plated at $3 \times 10^{4}-5 \times 10^{4}$ cells/well (50\% confluent) in 24-well plates, with $100 \mu \mathrm{L}$ of culture media each well. We transfected glioma cells with lncRNA-ANRIL-inhibitor, lncRNA negative control (lncRNA-NC), SOX9-inhibitor, and SOX9 negative control (SOX9-NC), respectively, and incubated them for $24 \mathrm{~h}$.

\section{Detection method}

qRT-PCR determination of InCRNA-ANRIL and SOX9 expression levels

Measurements of lncRNA-ANRIL and SOX9 levels in the serum and cells were done by qRT-PCR. Collect 5 $\mathrm{mL}$ of peripheral blood, and extract total RNA from the peripheral blood using the instructions of Trizol reagent. UV-3100PC (UV-Vis spectrophotometer) was utilized for the determination of RNA concentration and purity. The cDNA was then generated from the RNA via reverse-transcription, and then the qRT-PCR reaction was performed using lncRNA fluorescence quantitative detection kit (SYBR Green). GAPDH was used as a reference gene and CDNA as a template for PCR reaction. The reaction system was comprised of $10 \mu \mathrm{L}$ of SYBRPrimix Ex Taq (2x), 0.4 $\mu \mathrm{L}$ of $5^{\prime}$ primer, $0.4 \mu \mathrm{L}$ of $3^{\prime}$ primer, and $2.0 \mu \mathrm{L}$ of DNA template. Primer sequences are presented in Table 1 . PCR conditions: $95^{\circ} \mathrm{C}$ for $30 \mathrm{~s}$, followed by 40 cycles of $95^{\circ} \mathrm{C}$ for $5 \mathrm{~s}$, and $60^{\circ} \mathrm{C}$ for $40 \mathrm{~s}$. Each reaction was repeated 3 times, and the expression level was computed by the $2^{-\Delta \Delta C T}$ method.

\section{CCK8 assay for cell proliferation}

The cells were harvested $24 \mathrm{~h}$ after the transfection and seeded in 96 -well plates at $4 \times 10^{6}$ cells/well. At four timepoints $(0,24,48$, and $72 \mathrm{~h}$ after the cell culture), 10 $\mu \mathrm{L}$ of CCK8 solution and $90 \mu \mathrm{L}$ of basal medium (DMEM) were added to each well, and the plates were cultured at $37^{\circ} \mathrm{C}$ for $4 \mathrm{~h}$. Then the optical density (OD) of cells in each group was measured by a microplate reader at $450 \mathrm{~nm}$.

\section{Transwell assay for cell invasion}

Twenty-four hours after the transfection, cells were planted in 24-well plates at $3 \times 10^{4}$ cells/well. Then cells were digested by $0.25 \%$ trypsin and added to the apical chamber, together with $200 \mu \mathrm{L}$ of RPMI1640 solution, while $500 \mathrm{~mL}$ of RPMI1640 solution containing 10\% PBS was placed into the basolateral chamber. At $37^{\circ} \mathrm{C}$, the whole system was then cultured with $5 \% \mathrm{CO}_{2}$ for 24 $\mathrm{h}$. The matrix and cells in the apical chamber that did not migrate through the membrane surface were wiped away, followed by 3 times of PBS washing. A 10-min fixation was performed using paraformaldehyde, followed by 3 washes by double distilled water. The system was stained with $0.5 \%$ crystal violet when it got dried, then the cell invasion was observed under a microscope.

\section{Flow cytometry for cell apoptosis}

The treated cells were subjected to digestion with $0.25 \%$ trypsin and 2 washes with PBS. Next, $100 \mu \mathrm{L}$ of binding buffer was added to prepare a suspension of $1 \times 10^{6}$ cells/ $\mathrm{mL}$. This is followed by the addition of Annexin V-FITC and PI to perform the incubation at room temperature in the dark. Finally, the FC500MCL flow cytometry detection was repeated 3 times to obtain the mean value.

\section{Western Blot (WB) assay to detect bcl-2 and bax levels}

The RIPA lysis was performed on cells in each group to extract the total protein, whose concentration was then determined by BCA method. The protein concentration was made to $4 \mu \mathrm{g} / \mu \mathrm{L}$ to perform the electrophoretic separation by $12 \%$ SDS-PAGE. After the electrophoresis, the protein was transferred to a PVDF membrane and stained by the Ponceau S. Then the protein was immersed in PBST for $5 \mathrm{~min}$ and washed, and blocked with 5\% skim milk powder at ambient temperature for 2 h. After that, the system was blocked with bcl-2 (1:500), bax (1:500), and GAPDH primary antibody (1:1000) at $4^{\circ} \mathrm{C}$ overnight. Thereafter, the primary antibody was washed and the horseradish peroxidase-labeled secondary antibody (1:5000) was added to perform the incubation at $37^{\circ} \mathrm{C}$ for $1 \mathrm{~h}$, followed by 3 times of PBS rinse, 5 min each. The extra liquid on the film was blotted with a filter paper, and the ECL was conducted to perform development in the dark. The protein bands were finally

Table 1 Primer sequences

\begin{tabular}{lll}
\hline & Forward primer & Reverse primer \\
\hline LnCRNA-ANRIL & 5'-TGCTCTATCCGCCAATCAGG-3' & 5'-GGGCCTCAGTGGCACATACC-3' \\
SOX9 & 5'-AGTACCCGCACTTGCACAAC-3' & 5'-CGTTCTTCACCGACTTCCTC-3' $^{\prime}$ \\
GAPDH & 5'-GAGTCAACGGATTTGGTCGT-3' & 5'-TTGATTITGGAGGGATCTCG-3' \\
\hline
\end{tabular}


scanned to analyze the relative expression of bcl-2 and bax, with GAPDH as the internal reference.

\section{Endpoints}

SOX9 and lncRNA-ANRIL in the peripheral blood of the two cohorts of subjects was observed. Patients in IG were followed up for 3 years. Patients were divided into high- and low-lncRNA-ANRIL groups by the median expression of lncRNA-ANRIL, or into high- and lowSOX9 groups by the median expression of SOX9, for the comparison of the 3-year survival of patients. The relationship between lncRNA-ANRIL and SOX9 and clinical pathology in IG patients was analyzed. Cell proliferation, invasion, and apoptosis after transfection were observed. Bcl-2 and bax levels were measured.

\section{Statistical processing}

Statistical analysis was done by SPSS24.0 software (Shanghai Yuchuang Network Technology Co., Ltd.) and the data visualization by GraphPad 5 software. Intra-group comparisons were made by the independent $t$ test, multi- group comparisons by one-way ANOVA (denoted by F), and pairwise comparisons by the LSD $t$ test. Comparisons between multiple time points were performed by the repeated measures analysis of variance, and the post-hoc test by the Bonferroni test. The receiver operating characteristic (ROC) curve was drawn to demonstrate the diagnostic value of lncRNA-ANRIL and SOX9 for glioma. Differences were statistically significant when $P$ values $<0.05$.

\section{Results}

\section{Comparison of clinical data}

The two cohorts of subjects were comparable since they were not significantly different in age, sex ratio, tumor grade, tumor diameter, tumor location, distant metastasis, family history of glioma, smoking, and drinking $(P>0.05)$ Table 2.

\section{Serum IncRNA-ANRIL and SOX9 levels in glioma patients and their diagnostic significance for glioma} Serum lncRNA-ANRIL and SOX9 levels were evidently higher in RG than in CG $(P<0.01)$ (Fig. 1a, b). The area

Table 2 Comparison of clinical data [ $(\%)]$

\begin{tabular}{|c|c|c|c|c|}
\hline & Research group $(n=142)$ & Control group $(n=120)$ & $t$ or $x^{2}$ & $P$ \\
\hline Age (year) & $36.29 \pm 5.33$ & $35.12 \pm 4.62$ & 1.881 & 0.061 \\
\hline Sex & & & 0.728 & 0.393 \\
\hline Male & $89(62.68)$ & $69(57.50)$ & & \\
\hline Female & $53(37.32)$ & $51(42.50)$ & & \\
\hline \multicolumn{5}{|l|}{ Tumor grade } \\
\hline Grade I to II & $79(55.63)$ & & & \\
\hline Grade III to IV & $63(44.37)$ & & & \\
\hline Tumor diameter $(\mathrm{cm})$ & $4.51 \pm 1.27$ & & & \\
\hline \multicolumn{5}{|l|}{ Tumor location } \\
\hline Frontal lobe & $41(28.87)$ & & & \\
\hline Temporal lobe & $58(40.85)$ & & & \\
\hline Parietal lobe & $30(21.13)$ & & & \\
\hline Others & $13(9.15)$ & & & \\
\hline \multicolumn{5}{|l|}{ Distant metastasis } \\
\hline Yes & 39 (27.46) & & & \\
\hline No & $103(72.54)$ & & & \\
\hline Family history of glioma & & & 3.133 & 0.077 \\
\hline Yes & 19 (13.38) & $5(4.17)$ & & \\
\hline No & $123(86.62)$ & $115(93.33)$ & & \\
\hline Smoking & & & 0.257 & 0.612 \\
\hline Yes & $54(38.03)$ & $42(35.00)$ & & \\
\hline No & $88(61.97)$ & $78(65.00)$ & & \\
\hline Drinking & & & 0.541 & 0.462 \\
\hline Yes & $62(43.66)$ & $47(39.17)$ & & \\
\hline No & $80(56.34)$ & $73(60.83)$ & & \\
\hline
\end{tabular}




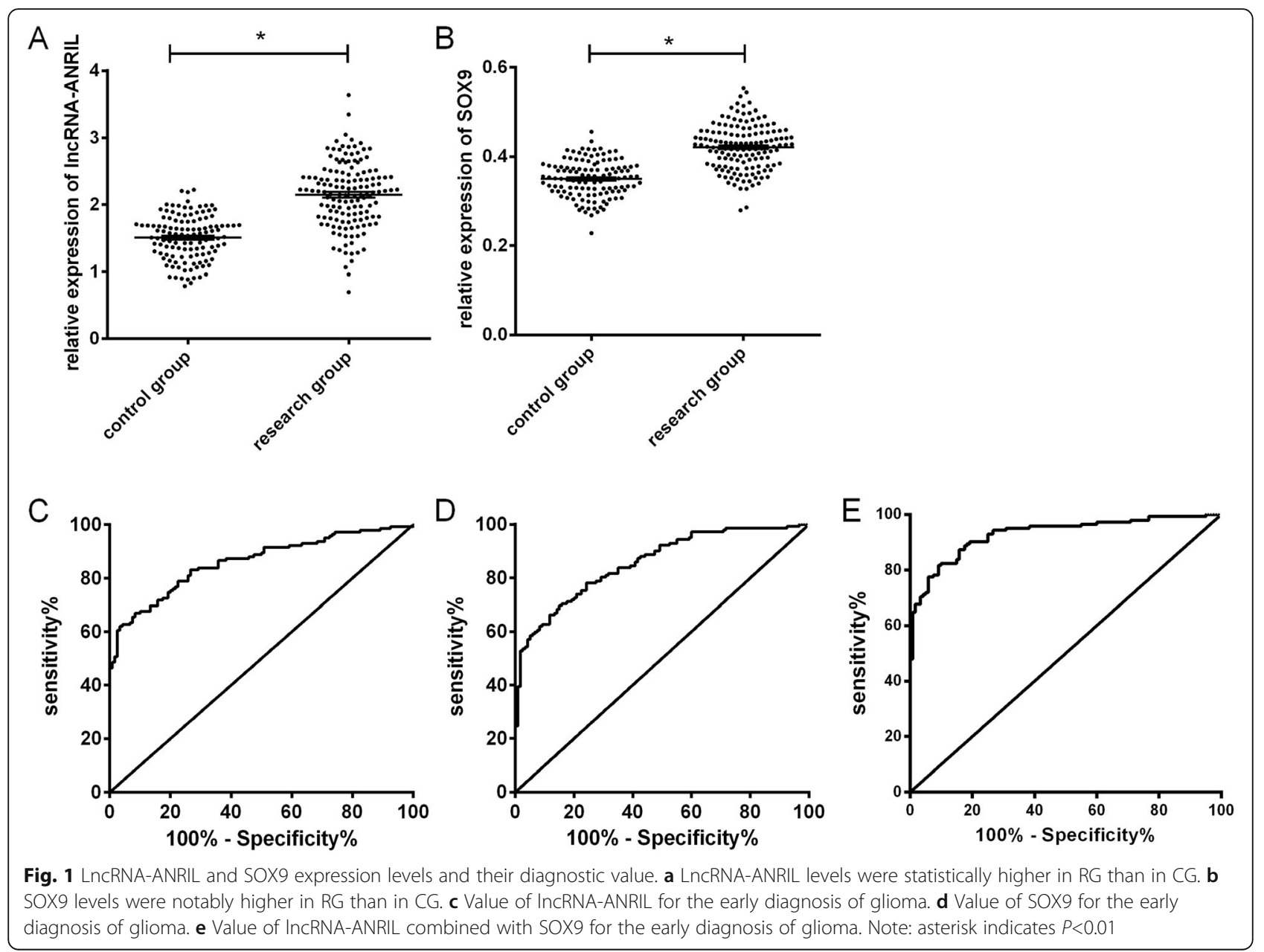

under the ROC curve (AUC) for glioma diagnosis was 0.860 for lncRNA-ANRIL (Fig. 1c) and 0.857 for SOX9 (Fig. 1d). In the combined detection of the two, RG was used as the independent variable, and a binary logistic analysis was performed to obtain the combined detection model: $\log (\mathrm{P})=17.377+(-3.505) \times \operatorname{lncRNA}$-ANRI $\mathrm{L}+(-29.307) \times$ SOX9. When the AUC of this model was 0.930 , the sensitivity was $81.62 \%$ and the specificity was $90.83 \%$ for diagnosing gliomas (Fig. 1e, Table 3).

Table 3 Value of IncRNA-ANRIL single detection, SOX9 single detection, and the combined detection for the early diagnosis of glioma

\begin{tabular}{llll}
\hline & IncRNA-ANRIL & SOX9 & Combined detection \\
\hline Cut-off & 2.018 & 0.395 & 0.388 \\
Sensitivity (\%) & 61.97 & 69.72 & 81.62 \\
Specificity (\%) & 96.67 & 85.00 & 90.83 \\
AUC & 0.860 & 0.857 & 0.930 \\
$95 \% \mathrm{Cl}$ & $91.69-99.08 \%$ & $77.33-90.86 \%$ & $84.19-95.33 \%$ \\
Std. error & 0.023 & 0.022 & 0.016 \\
$P$ & $<0.001$ & $<0.001$ & $<0.001$ \\
\hline
\end{tabular}

3. The relationship between IncRNA-ANRIL and SOX9 expression levels and the clinicopathology in patients with glioma

LncRNA-ANRIL and SOX9 were closely related to the increase in tumor grade, tumor diameter, distant metastasis, and family history of glioma $(P<0.01)$ Table 4 .

\section{Prognosis of patients}

Patients were divided into the high-lncRNA-ANRIL group $(\geq 2.16,61$ cases) and the low-lncRNA-ANRIL group $(<2.16,74$ cases) by the median expression of IncRNA-ANRIL, or into the high SOX9 group $(\geq 0.42,59$ cases) and the low SOX9 group $(<0.42,76$ cases $)$ by the median expression of SOX9. By May 2019, 135 patients in RG (95.07\%) have been successfully followed up by telephone, hospital review, and home visits. The 1-year, 2-year, and 3-year survival rates were 90.16\%, 78.69\%, and $63.93 \%$ in the high-lncRNA-ANRIL group, markedly lower than those in the low-lncRNA-ANRIL group (94.59\%, 89.19\%, and 81.08\%, $P=0.025$ ) (Fig. 2a). The high SOX9 group had distinctly lower 1-year, 2-year, and 3-year survival rates than the low SOX9 group 
Table 4 The relationship between IncRNA-ANRIL and SOX9 expression levels and the clinicopathology in patients with glioma

\begin{tabular}{|c|c|c|c|c|c|c|c|}
\hline Factors & $n$ & Relative expression of IncRNA-ANRIL & $t$ & $P$ & Relative expression of SOX9 & $t$ & $P$ \\
\hline Tumor grade & & & 8.650 & $<0.001$ & & 6.621 & $<0.001$ \\
\hline Grade I to II & 79 & $2.47 \pm 0.35$ & & & $0.39 \pm 0.04$ & & \\
\hline Grade III to IV & 63 & $2.02 \pm 0.27$ & & & $0.44 \pm 0.05$ & & \\
\hline Tumor diameter(cm) & & & 3.602 & $<0.001$ & & 6.638 & $<0.001$ \\
\hline$\geq 4.51$ & 77 & $2.29 \pm 0.31$ & & & $0.45 \pm 0.04$ & & \\
\hline$<4.51$ & 65 & $2.11 \pm 0.28$ & & & $0.41 \pm 0.03$ & & \\
\hline Distant metastasis & & & 5.351 & $<0.001$ & & 5.027 & $<0.001$ \\
\hline Yes & 39 & $2.38 \pm 0.27$ & & & $0.43 \pm 0.06$ & & \\
\hline No & 103 & $2.13 \pm 0.24$ & & & $0.38 \pm 0.05$ & & \\
\hline Family history of glioma & & & 2.166 & 0.032 & & 2.113 & 0.036 \\
\hline Yes & 19 & $2.26 \pm 0.37$ & & & $0.36 \pm 0.05$ & & \\
\hline No & 123 & $2.09 \pm 0.31$ & & & $0.40 \pm 0.08$ & & \\
\hline
\end{tabular}

(93.22\%, 79.66\%, and $64.41 \%$ vs. $96.05 \%, 89.47 \%$, and 80.26\%; $P=0.039$ ) (Fig. 2b).

\section{LncRNA-ANRIL expression in glioma cells and its} influence on cell multiplication, invasion, and apoptosis LncRNA-ANRIL was markedly higher in U251 and U87 cells than in normal HA $(P<0.01)$ (Fig. 3a). After transfection, lncRNA-ANRIL expression was markedly lower in U251 cells transfected with lncRNA-ANRIL-inhibitor than in U251 cells transfected with lncRNA-NC $(P<0.01)$ (Fig. 3b). Cells transfected with lncRNA-ANRIL-inhibitor had markedly lower multiplication and invasion and markedly higher apoptosis compared with those transfected with IncRNA-NC $(P<0.01)$ (Fig. $3 \mathrm{c}-\mathrm{e})$. WB assay revealed that cells transfected with lncRNA-ANRIL-inhibitor had markedly elevated bcl- 2 protein expression and reduced bax protein expression than those transfected with lncRNA-NC $(P<0.01)$ (Fig. $3 f)$.
6. SOX9 expression in glioma cells and its influence on cell multiplication, invasion, and apoptosis

The expression of SOX9 was markedly higher in U251 and U87 cells than in normal HA $(P<0.01)$ (Fig. 4a). After transfection, SOX9 expression was markedly lower in U251 cells transfected withSOX9-inhibitor than in those transfected with SOX9-NC $(P<0.01)$ (Fig. 4b). Cells transfected with SOX9-inhibitor had markedly reduced multiplication and invasion and markedly enhanced apoptosis compared with those transfected with SOX9-NC $(P<0.01)$ (Fig. 4c-e). WB assay revealed that cells transfected with SOX9-inhibitor had markedly higher bcl-2 protein expression and lower bax protein expression than cells transfected with SOX9-NC $(P<0.01)$ (Fig. 4f).

\section{Discussion}

Glioma is a common malignant brain tumor originating from the neuroectoderm, mainly distributed in the
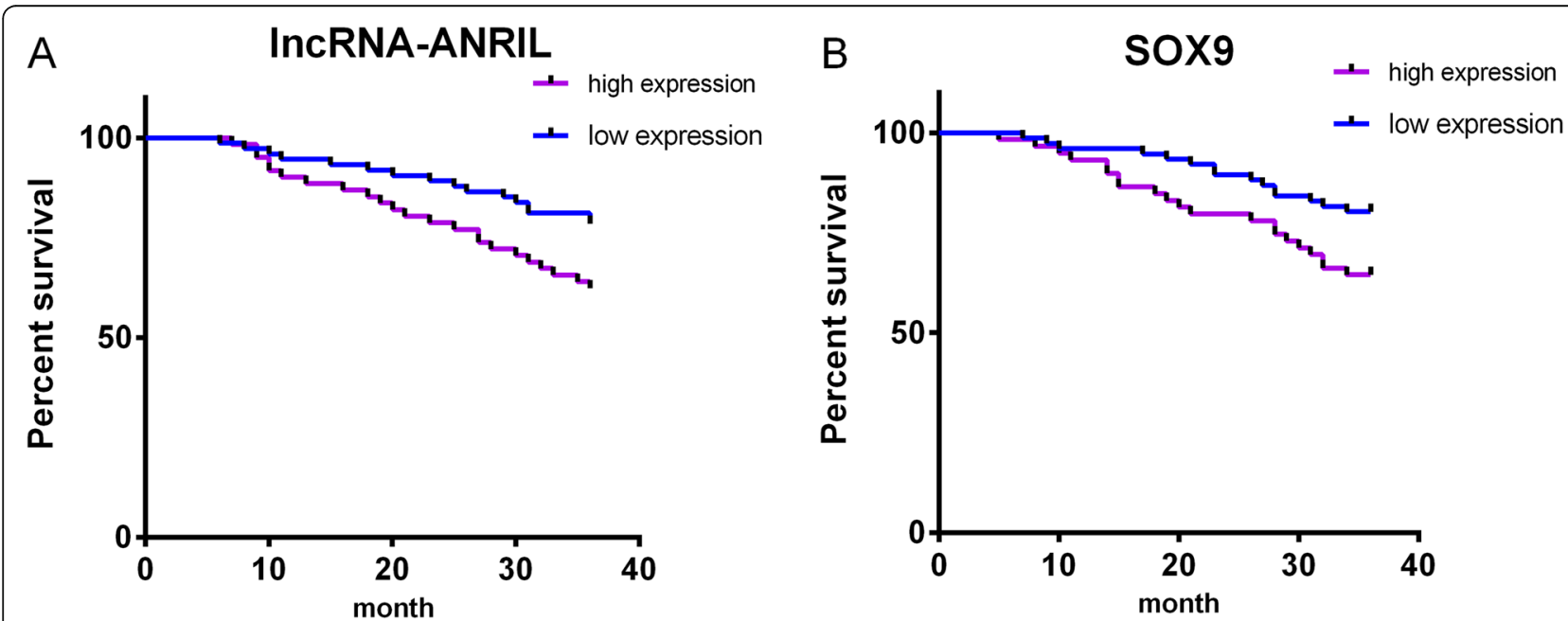

Fig. 2 Risk factors affecting the prognosis of glioma patients. a The relationship between IncRNA-ANRIL and the prognosis of patients. $\mathbf{b}$ The relationship between SOX9 and the prognosis of patients 


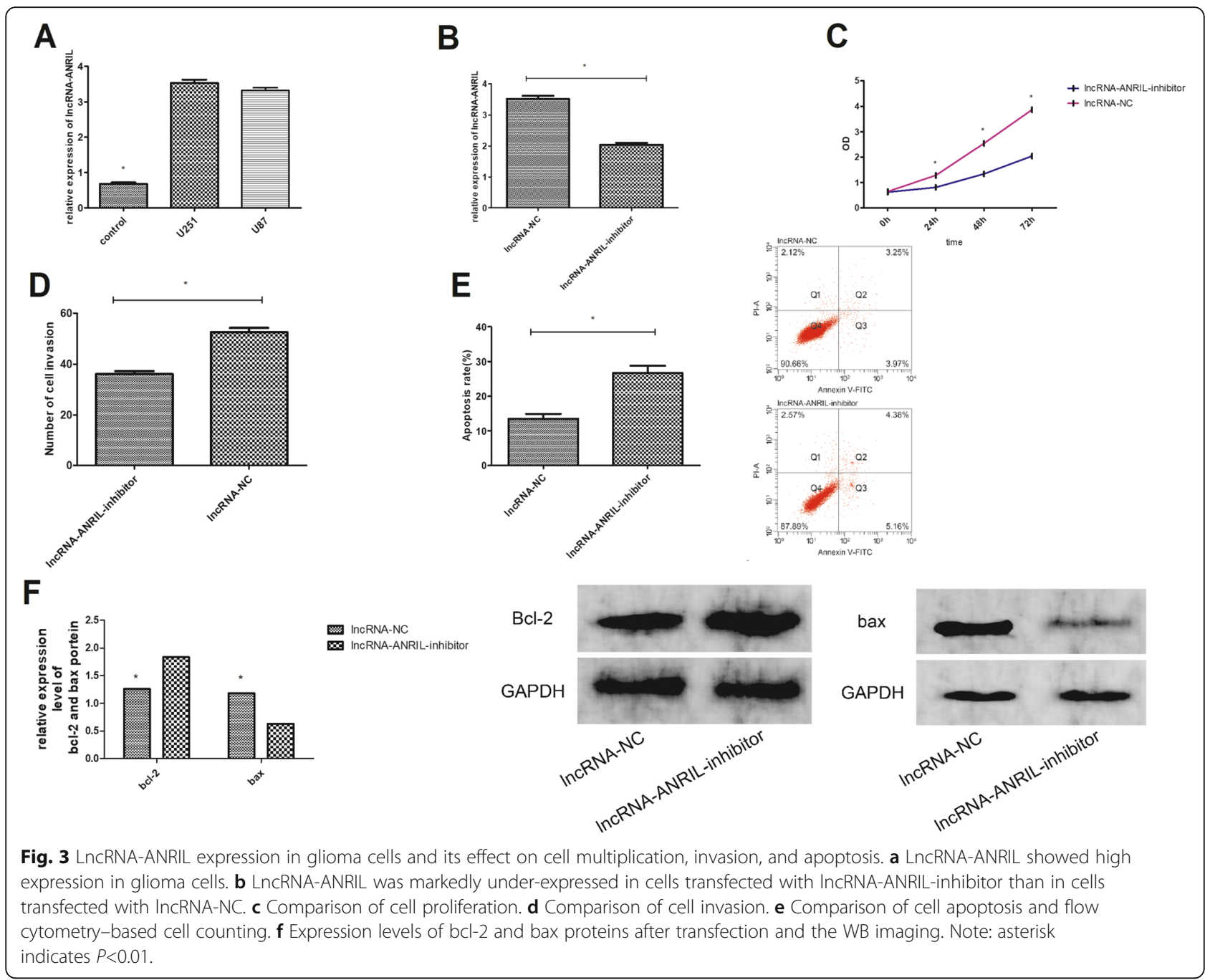

central and peripheral nervous systems of the human body, being the main reason for deaths from brain cancer [22]. It is featured with a high recurrence rate, a poor prognosis, and a yearly increase in its morbidity [23]. Glioma causes no marked discomfort in the early stage until its obvious clinical symptoms occur, accompanied by neurological deficits. Patients are already with grade III to IV malignant glioma tumors in infiltrative growth at the time of diagnosis, showing no clear demarcation between the invaded surrounding normal brain tissue and the tumor, which hinders the clinical treatment of glioma [24]. The existing common treatment for glioma is surgical resection followed by chemotherapy and radiotherapy $[25,26]$. Despite the advancement in glioma treatment methods, the puzzle of its underlying mechanism restricts the improvement in the overall treatment efficacy, leading to no reduction in its morbidity and mortality [27]. In recent years, a growing number of scholars have been working on the molecular pathogenesis of gliomas and its gene-related therapies [28,
29]. LncRNA is a type of non-coding RNA with over 200 bases. Among them, IncRNA-ANRIL, an antisense RNA located in the chromosome 9p21.3 with $3.8 \mathrm{~kb}$ in length, is expressed in various tissues in the human body [30, 31]. LncRNA-ANRIL has been identified as a genetic susceptibility site for a variety of cancers including intracranial aneurysms [32]. SOX9 is a part of the SRYrelated gene family, closely related to tumor development and progression [33, 34]. In-depth studies of glioma have revealed a close correlation of bcl-2 and bax with cell apoptosis. Bcl-2 is an apoptosis inhibitor, but bax is an apoptosis inducer [35]; hence, the determination of bcl-2 and bax levels can be used as a crucial judge of the malignancy of gliomas. The present study investigated lncRNA-ANRIL and SOX9 levels in gliomas and their effects on the biological functions of cells, aiming to enlighten new ways of diagnosis and treatment for gliomas in terms of molecular biology.

Here we employed qRT-PCR to determine serum lncRNA-ANRIL and SOX9 levels in glioma patients and 


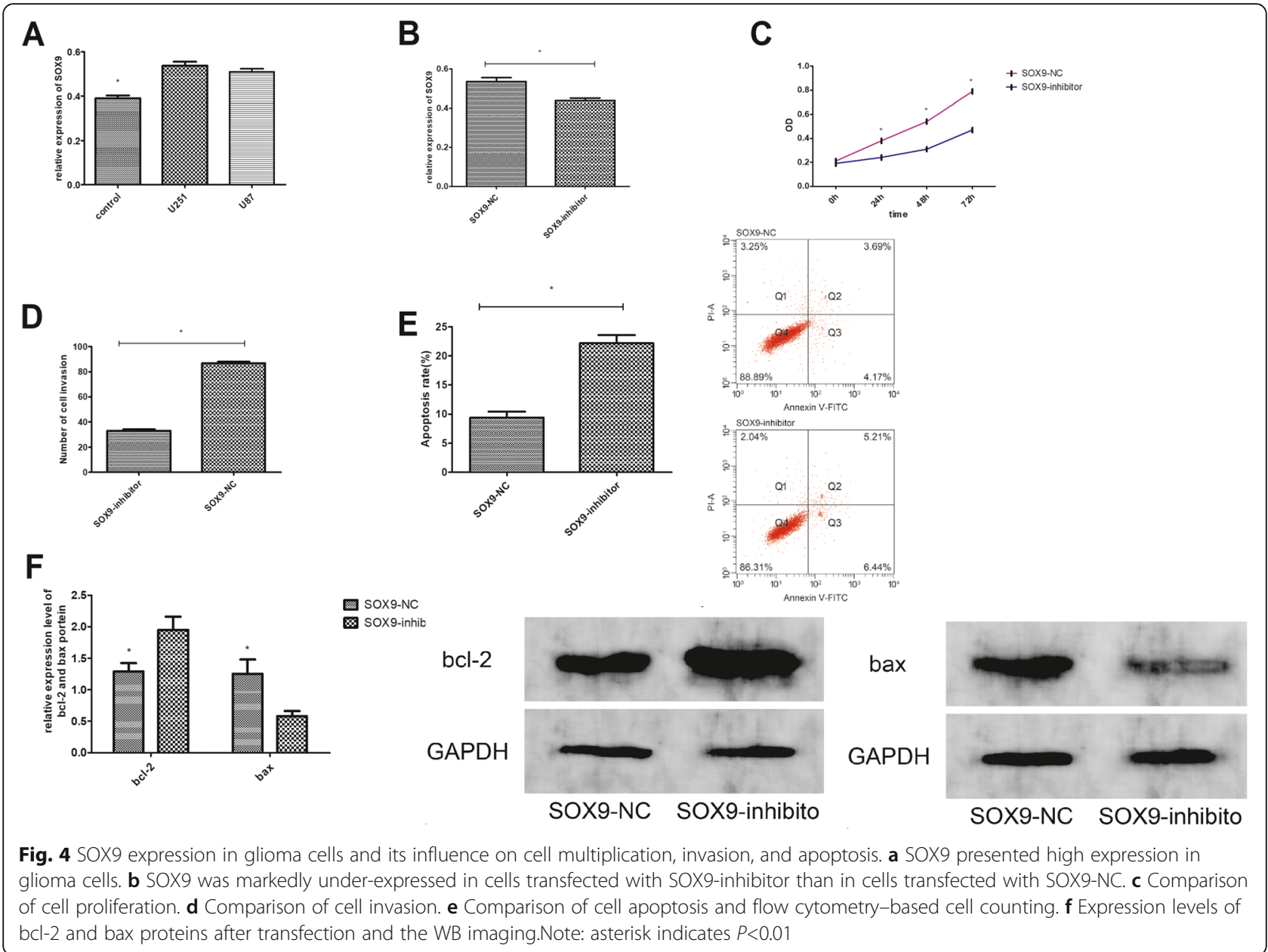

healthy adults and detected abnormally upregulated expression of the two in the serum of glioma patients. Sang et al. also found an upregulation of lncRNA-ANRI $\mathrm{L}$ and SOX9 expression in gliomas [36, 37], which is consistent with our results and supports our findings. The ROC curve revealed that when the cut-off value was 2.018, the sensitivity of IncRNA-ANRIL for glioma diagnosis was $61.97 \%$ and the specificity was $96.67 \%$; the sensitivity and the specificity of SOX9 for glioma diagnosis were $69.72 \%$ and $85.00 \%$, respectively, when the cutoff value was 0.395; and when the cut-off value was 0.388 , the combined diagnosis had higher sensitivity than the single diagnosis with lncRNA-ANRIL or SOX9. We further analyzed patients' clinicopathological characteristics and found that high-lncRNA-ANRIL and SOX9 levels were correlated with tumor grade, tumor diameter, distant metastasis, and family history of glioma. The 3-year survival was markedly higher in the highlncRNA-ANRIL group and high SOX9 group than in the low-IncRNA-ANRIL group and low SOX9 group, suggesting that IncRNA-ANRIL and SOX9 are related to the prognosis of patients with glioma. So we can monitor lncRNA-ANRIL and SOX9 expression to improve the prognosis of patients. The above results conclude that IncRNA-ANRIL and SOX9 are closely related to the development and progression of gliomas. In our research, IncRNA-ANRIL and SOX9 were higher in U251 and U87 cells than in HA, which is consistent with our previous research results. The expression of IncRNA-ANRIL and SOX9 was markedly reduced in U251 cells by gene downregulation. Then we transfected lncRNA-ANRIL-inhibitor, IncRNA-NC, SOX9-inhibitor, and SOX9-NC to U251 cells to observe the changes in the cell biological functions. Cell proliferation and invasion were restricted after the suppression of IncRNAANRIL and SOX9 expression, but the cell apoptosis was remarkably stimulated, which is consistent with the results of Dai et al. [38, 39]. Cells transfected with IncRNA-ANRIL-inhibitor and SOX9-inhibitor had higher bcl-2 levels and lower bax levels compared with cells transfected with lncRNA-NC and SOX9-NC, which is consistent with the results of Jia et al. [40]. Such results suggest that glioma cell proliferation and invasion can be controlled by silencing lncRNA-ANRIL and 
SOX9. However, the underlying mechanisms of the two to affect the molecular biological functions of glioma cells are not clear.

Here we confirmed high expression of lncRNA-ANRIL and SOX9 in glioma and proved that the inhibition of lncRNA-ANRIL and SOX9 can modulate the multiplication, invasion, and apoptosis of glioma cells. This study is subjected to some limitations. For example, the limited experimental conditions hindered us to figure out the specific regulatory network of lncRNA-ANRIL and SOX9 to affect glioma. We will supplement our conclusions with data in follow-up studies.

\section{Conclusions}

In summary, lncRNA-ANRIL and SOX9 levels were higher in glioma patients than in healthy people. The high expression of IncRNA-ANRIL and SOX9 was closely associated with the unfavorable prognosis of patients. The testing of biological behaviors revealed that lncRNA-ANRIL and SOX9 worked as tumor-promoting genes in glioma.

\section{Acknowledgements}

Not applicable.

\section{Authors' contributions}

YS designed the study and drafted the manuscript. YJ was responsible for the collection and analysis of the experimental data. $Y Z$ revised the manuscript critically for important intellectual content. The authors have read and approved the final manuscript.

\section{Funding}

Not applicable.

\section{Availability of data and materials}

The datasets used and/or analyzed during the current study are available from the corresponding author on reasonable request.

\section{Declarations}

\section{Ethics approval and consent to participate}

The study was approved by the Ethics Committee of Guangrao County People's Hospital, China. Signed written informed consents were obtained from the patients and/or guardians.

\section{Consent for publication}

Not applicable.

\section{Competing interests}

The authors declare that they have no competing interests.

\section{Author details}

${ }^{1}$ Department of Neurosurgery, Guangrao County People's Hospital, No. 180 Huayuan Road, Dongying, Guangrao County 257300, P.R. China. ${ }^{2}$ Department of Neurosurgery, The Second People's Hospital Of Dongying, Dongying 257335, P.R. China.

Received: 23 March 2021 Accepted: 3 September 2021

Published online: 23 September 2021

\section{References}

1. Weller M, Wick W, Aldape K, Brada M, Berger M, Pfister SM, et al. Glioma. Nat Rev Dis Primers. 2015;1(1):15017. https://doi.org/10.1038/nrdp.2015.17.

2. Jiang $B$, Liu H, Sun D, Sun $H, R u X$, Fu J, et al. Mortality due to primary brain tumours in China and detection rate in people with suspected symptoms: a nationally representative cross-sectional survey. World J Surg Oncol. 2021; 19(1):71. https://doi.org/10.1186/s12957-021-02179-5.

3. Bakas S, Akbari H, Sotiras A, Bilello M, Rozycki M, Kirby JS, et al. Advancing The Cancer Genome Atlas glioma MRI collections with expert segmentation labels and radiomic features. Sci Data. 2017;4(1):170117. https://doi.org/10.1 038/sdata.2017.117.

4. He Y, Yu X, Zhang M, Guo W. Pan-cancer analysis of $m(5) C$ regulator genes reveals consistent epigenetic landscape changes in multiple cancers. World J Surg Oncol. 2021;19(1):224. https://doi.org/10.1186/s12957-021-02342-y.

5. Ostrom QT, Bauchet L, Davis FG, Deltour I, Fisher JL, Langer CE, et al. The epidemiology of glioma in adults: a "state of the science" review. Neuro Oncol. 2014;16(7):896-913. https://doi.org/10.1093/neuonc/nou087.

6. Lenting K, Verhaak R, Ter Laan M, Wesseling P, Leenders W. Glioma: experimental models and reality. Acta Neuropathol. 2017;133(2):263-82. https://doi.org/10.1007/s00401-017-1671-4.

7. Jovcevska I, Kocevar N, Komel R. Glioma and glioblastoma - how much do we (not) know? Mol Clin Oncol. 2013;1(6):935-41. https://doi.org/10.3892/ mco.2013.172

8. Dunet V, Pomoni A, Hottinger A, Nicod-Lalonde M, Prior JO. Performance of 18F-FET versus 18F-FDG-PET for the diagnosis and grading of brain tumors: systematic review and meta-analysis. Neuro Oncol. 2016;18(3):426-34. https://doi.org/10.1093/neuonc/nov148.

9. Buckner JC, Shaw EG, Pugh SL, Chakravarti A, Gilbert MR, Barger GR, et al. Radiation plus Procarbazine, CCNU, and Vincristine in low-grade glioma. N Engl J Med. 2016;374(14):1344-55. https://doi.org/10.1056/NEJMoa1500925.

10. Hu Z, Fang C, Li B, Zhang Z, Cao C, Cai M, et al. First-in-human liver-tumour surgery guided by multispectral fluorescence imaging in the visible and near-infrared-I/II windows[J]. Nat Biomed Eng. 2020;4(3):259-71. https://doi. org/10.1038/s41551-019-0494-0.

11. Ottenhausen M, Krieg SM, Meyer B, Ringel F. Functional preoperative and intraoperative mapping and monitoring: increasing safety and efficacy in glioma surgery. Neurosurg Focus. 2015;38(1):E3. https://doi.org/10.3171/2 014.10.FOCUS14611.

12. Qin C, Zhong J, Hu Z, Yang X, Tian J. Recent advances in Cerenkov luminescence and tomography imaging[J]. IEEE J Selected Topics Quantum Electronics. 2011;18(3):1084-93. https://doi.org/10.1109/JSTQE.2011.2161757.

13. Yang G, Lu X, Yuan L. LncRNA: a link between RNA and cancer. Biochim Biophys Acta. 1839;2014(11):1097-109. https://doi.org/10.1016/j.bbagrm.2 014.08.012.

14. Yang J, Zhang JY, Chen J, Chen C, Song XM, Xu Y, et al. Prognostic role of microRNA-145 in various human malignant neoplasms: a meta-analysis of 18 related studies. World J Surg Oncol. 2014;12(1):254. https://doi.org/10.11 86/1477-7819-12-254.

15. Balci T, Yilmaz Susluer S, Kayabasi C, Ozmen Yelken B, Biray Avci C, Gunduz C. Analysis of dysregulated long non-coding RNA expressions in glioblastoma cells. Gene. 2016;590(1):120-2. https://doi.org/10.1016/j.gene.2 016.06.024.

16. Xu Y. MicroRNA-136-3p inhibits glioma tumorigenesis in vitro and in vivo by targeting KLF7. World J Surg Oncol. 2020;18(1):169. https:/doi.org/10.1186/ s12957-020-01949-X.

17. Dong $X$, Jin Z, Chen $Y, X u H, M a C$, Hong $X$, et al. Knockdown of long noncoding RNA ANRIL inhibits proliferation, migration, and invasion but promotes apoptosis of human glioma cells by upregulation of miR-34a. J Cell Biochem. 2018;119(3):2708-18. https://doi.org/10.1002/jcb.26437.

18. Ruan H, Hu S, Zhang H, Du G, Li X, Li X, et al. Upregulated SOX9 expression indicates worse prognosis in solid tumors: a systematic review and metaanalysis. Oncotarget. 2017;8(68):113163-73. https://doi.org/10.18632/oncota rget.22635.

19. Lu F, Li C, Sun Y, Jia T, Li N, Li H. Upregulation of miR-1825 inhibits the progression of glioblastoma by suppressing CDK14 though Wnt/betacatenin signaling pathway. World J Surg Oncol. 2020;18(1):147. https://doi. org/10.1186/s12957-020-01927-3.

20. Wang L, He S, Yuan J, Mao X, Cao Y, Zong J, et al. Oncogenic role of SOX9 expression in human malignant glioma. Med Oncol. 2012;29(5):3484-90. https://doi.org/10.1007/s12032-012-0267-z.

21. Larsimont JC, Youssef KK, Sanchez-Danes A, Sukumaran V, Defrance M, Delatte $B$, et al. Sox9 controls self-renewal of oncogene targeted cells and links tumor initiation and invasion. Cell Stem Cell. 2015;17(1):60-73. https:// doi.org/10.1016/j.stem.2015.05.008.

22. Ludwig K, Kornblum HI. Molecular markers in glioma. J Neuro-Oncol. 2017; 134(3):505-12. https://doi.org/10.1007/s11060-017-2379-y. 
23. Hervey-Jumper SL, Berger MS. Maximizing safe resection of low- and highgrade glioma. J Neuro-Oncol. 2016;130(2):269-82. https://doi.org/10.1007/ s11060-016-2110-4.

24. Gutmann DH. The tropism of pleiotrophin: orchestrating glioma brain invasion. Cell. 2017;170(5):821-2. https://doi.org/10.1016/j.cell.2017.08.011.

25. Liebelt BD, Shingu T, Zhou X, Ren J, Shin SA, Hu J. Glioma stem cells: signaling, microenvironment, and therapy. Stem Cells Int. 2016;2016: 7849890-10. https://doi.org/10.1155/2016/7849890.

26. Song T, Liu X, Qu Y, et al. A novel endoscopic Cerenkov luminescence imaging system for intraoperative surgical navigation[J]. Mol Imaging. 2015; 14(8):7290.2015. 00018

27. Strickland M, Stoll EA. Metabolic reprogramming in glioma. Front Cell Dev Biol. 2017:5:43. https://doi.org/10.3389/fcell.2017.00043.

28. Wang Q, Hu B, Hu X, Kim H, Squatrito M, Scarpace L, et al. Tumor evolution of glioma-intrinsic gene expression subtypes associates with immunological changes in the microenvironment. Cancer Cell. 2017;32:42-56 e46.

29. Zacher A, Kaulich K, Stepanow S, Wolter M, Kohrer K, Felsberg J, et al. Molecular diagnostics of gliomas using next generation sequencing of a glioma-tailored gene panel. Brain Pathol. 2017;27(2):146-59. https://doi.org/1 $0.1111 /$ bpa.12367.

30. Zou ZW, Ma C, Medoro L, Chen L, Wang B, Gupta R, et al. LncRNA ANRIL is up-regulated in nasopharyngeal carcinoma and promotes the cancer progression via increasing proliferation, reprograming cell glucose metabolism and inducing side-population stem-like cancer cells. Oncotarget. 2016;7(38):61741-54. https://doi.org/10.18632/oncotarget.11437.

31. Ma J, Li T, Han X, Yuan H. Knockdown of LncRNA ANRIL suppresses cell proliferation, metastasis, and invasion via regulating miR-122-5p expression in hepatocellular carcinoma. J Cancer Res Clin Oncol. 2018;144(2):205-14 https://doi.org/10.1007/s00432-017-2543-y.

32. Pasmant E, Sabbagh A, Vidaud M, Bieche I. ANRIL, a long, noncoding RNA, is an unexpected major hotspot in GWAS. FASEB J. 2011;25(2):444-8. https:// doi.org/10.1096/fj.10-172452.

33. Guo X, Xiong L, Sun T, Peng R, Zou L, Zhu H, et al. Expression features of SOX9 associate with tumor progression and poor prognosis of hepatocellular carcinoma. Diagn Pathol. 2012;7(1):44. https://doi.org/10.11 86/1746-1596-7-44.

34. Prevostel C, Rammah-Bouazza C, Trauchessec H, Canterel-Thouennon L, Busson M, Ychou M, et al. SOX9 is an atypical intestinal tumor suppressor controlling the oncogenic Wnt/ss-catenin signaling. Oncotarget. 2016;7(50): 82228-43. https://doi.org/10.18632/oncotarget.10573.

35. Zhao X, Wang P, Liu J, Zheng J, Liu Y, Chen J, et al. Gas5 Exerts Tumorsuppressive functions in human glioma cells by targeting miR-222. Mol Ther. 2015;23(12):1899-911. https://doi.org/10.1038/mt.2015.170.

36. Sang Q, Liu X, Sun D. Role of miR-613 as a tumor suppressor in glioma cells by targeting SOX9. Onco Targets Ther. 2018;11:2429-38. https://doi.org/1 $0.2147 / 0 T$ T156608

37. Paul Y, Thomas S, Patil V, Kumar N, Mondal B, Hegde AS, et al. Genetic landscape of long noncoding RNA (IncRNAs) in glioblastoma: identification of complex IncRNA regulatory networks and clinically relevant IncRNAs in glioblastoma. Oncotarget. 2018;9(51):29548-64. https://doi.org/10.18632/ oncotarget.25434.

38. Dai W, Tian C, Jin S. Effect of IncRNA ANRIL silencing on anoikis and cell cycle in human glioma via microRNA-203a. Onco Targets Ther. 2018;11: 5103-9. https://doi.org/10.2147/OTT.S169809.

39. Xu X, Wang Z, Liu N, Cheng Y, Jin W, Zhang P, et al. Association between SOX9 and CA9 in glioma, and its effects on chemosensitivity to TMZ. Int J Oncol. 2018;53(1):189-202. https://doi.org/10.3892/ijo.2018.4382.

40. Jia G, Wang Q, Wang R, Deng D, Xue L, Shao N, et al. Tubeimoside-1 induces glioma apoptosis through regulation of bax/bcl-2 and the ROS/ Cytochrome C/Caspase-3 pathway. Onco Targets Ther. 2015;8:303-11. https://doi.org/10.2147/OTT.S76063.

\section{Publisher's Note}

Springer Nature remains neutral with regard to jurisdictional claims in published maps and institutional affiliations. 